\title{
The ABCs of teaching alphabet knowledge: Affordances and challenges of 'weaving' visible and invisible pedagogies
}

\author{
Beryl Exley \\ Faculty of Education \\ Cultural and Language Studies in Education \\ Queensland University of Education \\ Australia \\ Ariane Richard-Bossez \\ Department of Sociology \\ University of Aix-Marseille \\ France
}

Dr Beryl Exley

Faculty of Education

Queensland University of Queensland

PO Box 2434

Brisbane

Queensland 4001

Australia

Professor Ariane Richard-Bossez

Department of Sociology

Aix-Marseille University; and

LAMES

MMSH - Maison méditerranéenne des sciences de l'Homme

5 rue du Château de l'Horloge, BP 647

13094 Aix-en-Provence cedex 2

France

Website link: http://www.lames.cnrs.fr/spip.php?article31

BERYL EXLEY is an Associate Professor in the Faculty of Education at the Queensland University of Technology, Australia. She teaches and researches in language and literacy education across the years of school. She has a special interest in curriculum literacies, in particular, the interface between grammar and critical literacy. In 2012 Beryl was a visiting scholar Aix-Marseille Universite, affiliated with the LAMES (Laboratoire Mediterraneen de Sociologie). Beryl can be contacted on b.exley@qut.edu.au

ARIANE RICHARD-BOSSEZ has been a nursery school teacher in France for 15 years. She is currently a PhD student in the department of sociology of the University of Aix-Marseille, France. Her research concerns the links between pedagogy and school disparities at French preschool, in particular in the field of literacy. She is affiliated with the LAMES (Laboratoire Méditerranéen de Sociologie). Ariane can be contacted on a.richardbossez@aliceadsl.fr

The work contained in this paper is our original composition and contains no material that has been previously published or submitted elsewhere except where due reference is made. 


\title{
The ABCs of teaching alphabet knowledge: Affordances and challenges of 'weaving' visible and invisible pedagogies
}

\author{
Published article citation: Exley, B. \& Richard-Bossez, A. (2013). The ABCs of teaching \\ alphabet knowledge: Challenges \& affordances of weaving visible \& invisible pedagogies.
} Contemporary Issues in Early Childhood. 14, 4, 345-356.

\begin{abstract}
As researchers interested in the pursuit of high quality/high equity literacy learning outcomes, we focus on the learning experiences of five early years French students, with a special regard for those who are already considered as being at-risk of educational failure. We narrow the empirical focus to a single lesson on a mechanical concept of print, that is matching lower and upper case alphabet letters. In doing so, we examine a deeply philosophical question: Which pedagogical practices dis/enable what sorts of early years students as literacy learners? We extend Cazden's (2006) notion of 'weaving' knowledge across dimensions of knowing to describe how the case study teacher 'weaves' visible and invisible pedagogies over the four movements of a lesson. The findings reveal different pedagogical framings (Bernstein, 1996) have potentially different cognitive and social effects that constitute different kinds of literacy knowledge and oppressive subject positions for atrisk students (Young, 1990).
\end{abstract}

\section{The place of alphabet knowledge in literacy learning}

We are researchers interested in the pursuit of social justice, a concept that 'refers to the aim of realising equal opportunities and life chances' not so much through 'compensating for exclusion' but through 'investing in inclusion' (Schraad-Tischler, 2011, p. 11). We subscribe to a concept of social justice that is 'concerned with guaranteeing each individual genuinely equal opportunities for self-realisation through the targeted investment in the development of individual 'capabilities"' (Schraad-Tischler, 2011, p. 11, emphasis in original). We note that the abounding inequities in early childhood classrooms have been documented in various countries over a period of time: France (Duru-bellat, 2003), Australia (Woods \& Henderson, 2008), the United Kingdom (Bernstein, 1977) and the United States (Heath, 1983). Each of these studies has implicitly highlighted the complex relationship between social justice and literacy teaching and learning. Literacy learning outcomes occupy a special position in our 
examination of social justice in early childhood education for two interrelated reasons. The first is that mastering the full range of literacy competences includes not only the technical skills for learning, but also the resources for viewing and constructing the world (Freire \& Macdeo, 1987). The second is that, as Janks (2010) documents, 'issues of access and diversity are tied to issues of power; to questions of domination and subordination; to processes of legitimation and negation, of inclusion and exclusion' (p.12). By way of example, in the French case, Leroy-Audouin's (1993, cited in Duru-Bellat, 2003) study shows that for four to five year old students, differences in social background has a strong correlation with the development of early reading knowledges and skills. Examining the pedagogic practices by which young students acquire the cognitive skills for literacy learning is thus an examination of one part of the complex relationship between literacy learning and social justice.

The influential work of Luke and Freebody (1999) theorises that a literate person consolidates and expands their knowledge, skills and understandings of the world through four interrelated practices: code breaking practices (knowing and using the alphabetic code of written text); text participation (drawing on knowledge of a topic and text to make meaning); text user (taking part in social activities to which a text is integral); and, text analyst practices (critically analysing how a text tries to position readers within a particular world view). Rather than seeing literacy as the accumulation of technical skills alone, concepts Paris (2005) conceptualizes as 'constrained skills', the viewpoint to which researchers such as Luke and Freebody as well as ourselves subscribe to, treats literacy as a dialectic that evolves from, is situated in, and contributes to a social arena (Halliday, 1978). We do not shy away from this position just because we are focusing on students in the early years of schooling; to the contrary, we support active engagement with all four resources for all students, even those who are struggling with constrained reading skills and are thus deemed at-risk of educational failure (Exley, 2008).

According to this way of understanding literacy, mastering code breaking practices for matching lower and upper case letters is one important outcome amongst many for students in the earliest years of school. Over a quarter of a century of research has demonstrated that developing alphabet knowledge in pre- and early readers is a strong but not perfect predictor of early reading and spelling success (Ball \& Blachman, 1991; Bowey, 2005). Although Paris (2005) cautions that the distribution of data for highly constrained skills such as alphabet 
knowledge are highly variable and unstable over time, the outcomes seem to hold consistent for a range of languages, including English (McBride-Chang, 1999), Israeli (Levin, Patel, Margalit \& Barad, 2002), German (Naslund \& Schneider, 1996) and Portuguese (CardosoMartins, Resende \& Rodrigues, 2002). Likewise, significant (but not perfect) correlations are found between the composite score on letter-name/letter-sound knowledge and early oral reading performances of French-speaking kindergarten children assessed over two time periods using a word/picture reading task (Sprenger-Charolles \& Bonnet, 1996). However, these findings do not demonstrate the same consistency for the young Finish participants in Salonen, Lepola and Niemi’s (1998) case study. Seymour, Aro and Erskine (2003) purport that Finish, like Greek, Italian and German, are languages with a shallow (consistent) graphophonic correspondence and in a structural sense sit apart from languages with a deeper (inconsistent) grapho-phonic correspondence, such as French, Portuguese, Danish and English. Whilst this latter explanation does not account for the tensions noted above, it still draws attention to the fact that the relationship between phonemes (sounds), graphemes (letters) and graphophonemic (letter-sound) relationships are experienced somewhat similarly across English and French at least. This being the case, the research literature that examines the acquisition of alphabet knowledge in early years English language contexts may be helpful to understanding the situation in France given the dearth of research literature that exists for this context.

It has long been accepted that irrespective of the target language, children begin to make meaning of the print world through the context in which text occurs. They initially 'read' (in the broadest sense of the word) using environmental clues and visual patterns for whole words, not necessarily attending to the individual letters within words (Hallet, 2008). Then, at some point, mastery of alphabet knowledge, which according to Worden and Boettche (1990) includes letter order recitation, naming individual letters, manually scribing upper and lower case letters and the association of letters with sounds and words, serves as a useful foundation for developing more formal print-based reading and writing (spelling) skills. According to empirical research undertaken in the United States with 180 English speaking children in California ranging in age from 2.5 to 7.5 years (Worden \& Boettche, 1990), the alphabet knowledges listed above all belong to the same general system of knowledge, but develop at different rates depending on experience, and in the case of naming individual letters, are acquired on a letter-by-letter basis, rather than as an entire set. The research identified stable sets of letters that were deemed easier or harder to master, and 'these tend to be the same for 
children as they grow older, as shown in the between-age rank-order correlations' (p. 290). In the same study, and in line with other literature which focuses exclusively on French beginning readers (Ecalle, Magnan \& Biot-Chevrier, 2008), young children perform better on upper than lower case naming and letter scribing tasks, with some letters proving more challenging, for example, upper case ' $Z$ ', and less challenging, for example, lower case ' $i$ '. The privileging of upper case letters is thought to be a factor of its greater visual simplicity and distinctiveness (Bissex, 1980), protypicalness and high level of occurrence in the texts with which young children engage, for example, titles, signs, advertising, alphabet books and toys (Worden \& Boettche, 1990). Paris (2005) makes three important points about the mastery of a highly constrained skill set such as alphabet knowledge: mastery can be 'completed' (unlike mastery of an unconstrained skill such as vocabulary which always remains incomplete); the duration of learning is relatively brief, and although individuals undertake their learning at different ages, all follow a sigmoid growth function (an S-shaped curve) 'in which initial acquisition of a skill is slow, followed by a period of rapid learning, and then followed by a slower rate of growth as asymptotic performance is approached' (p.190).

In this article, we review a group work activity on lower to upper case transcription as it was observed in a low-socio-economic, multilingual, multicultural classroom. Identifying congruence between lower and upper case letters is often a focus of teaching and learning tasks in the early years throughout the world. We draw on and overtly extend Cazden's (2006) notion of 'weaving' as the 'moments in classroom lessons when explicit connections are made - by teachers or students' between the 'known and the new' (p.1). Whilst Cazden (2006) specifically focused on the nature of the connections between knowledge types, Kwek (2012) observed that weaving a web of known and new knowledge connections into a more integrated knowledge experience 'implies the need to embrace a pedagogy that dares to disrespect boundaries between knowledge, context and time' (p.337). Thus we focus on the pedagogical practices for 'weaving' forms of knowledge, making note of the way the teacher moves between, or 'weaves', disparate pedagogical practices.

Our goal is informed by our concern for socially just literacy learning outcomes, that is, to recall Schraad-Tischer (2011), teaching and learning practices that guarantee 'each individual genuinely equal opportunities for self-realisation through the targeted investment in the development of individual 'capabilities"' ( p. 11, emphasis in original).Thus our research 
question is as follows: 'Which pedagogical practices dis/enable what sorts of early years students as literacy learners?' Our analytical focus is on the principles of transmission and acquisition woven throughout the four movements of one lesson.

The next section of this paper introduces the theoretical framework for referring to the specific pedagogic practices and revealing what forms of knowledge and pedagogic identities are made available to which individuals. The section after introduces the case study context, the teacher, Marie, and five of her multi-lingual multi-cultural Francophone student as participants. The analysis section theorises the pedagogical turns and the concluding discussion considers how weaving visible and invisible pedagogies dis/enables individual students as literacy learners and as participants in the pedagogic act. The conclusion highlights the considerable variation of opportunities made available to individual students, thus exposing socially un/just interactions of literacy teaching and learning.

\section{A theory for analysing pedagogic practices}

The theory which informs our analytical work is drawn from the published works of Basil Bernstein and his proposition to elaborate a sociology of knowledge, pedagogy and society (1996). For him, the sociology of education should be intensely interested in the relation to pedagogy as the way of reproducing external relations of power such as social class relations. The outcome of his theoretical project was a sociological theory capable of identifying, naming and explaining the nature, processes and outcomes of disparate forms of cultural transmission inherent in the stages of the pedagogic act. Attention is drawn to the relations of transmission and acquisition between teacher and taught, known theoretically as framing. At its most abstract, framing refers to the social relations of a given social division of labour. Stavrou (2011) refers to framing as an index capable of 'revealing the principles of social selection operating at the level of knowledge' (p.150). At a more practical level, framing refers to the locus of control over the selection, sequencing, pacing and criteria of the pedagogic discourse to be acquired (Bernstein, 1996). Pedagogic discourse serves as a principle for the transmission of two types of discourse: the instructional discourse, which is concerned with the content knowledge, and the regulative discourse, which is concerned with the choices for conduct, character and manner (Bernstein, 1996). As the regulative discourse 
produces the social order of the pedagogic act, regulative discourse is said to dominant the instructional discourse (Bernstein, 1996).

When framing is stronger, control of the instructional and regulative discourses lies with the teacher or the teacher's proxy, for example, a worksheet. Under these conditions, the pedagogical practice is more 'visible' and the rules of pedagogic discourse are explicit for the learners. If the framing is weaker, the learner appears to control the pedagogic discourses. We say 'appears' as students rarely, if ever, have full control of pedagogic discourses. Control in this case is said to tend towards 'invisible' because the rules of engagement seem to be known by the students. By way of example, Bernstein (1977) and Cloran (2000) demonstrate how Western preschools tend towards invisible pedagogies, thereby privileging mainstream middle class students who recognize the relatively invisible pedagogic codes but disenfranchising, or to use Young's (1990) term, 'marginalising', those from working and welfare class or minority language and cultural groups who struggle to recognize the pedagogic codes, and thus likewise struggle to access the instructional discourse. From the viewpoint of social justice, Young (1990) claims marginalisation is perhaps the most dangerous form of oppression. Remediating the inequities of marginalisation, Ramognino (2011) counters, is not to be lured into the temptation of binaries that operate 'between' but to analyse relations 'within' the specific inner activity of the classroom (p.53). As a case in point, Pandraud's (2011) study of young teenagers undertaking French language lessons in Marseilles (France) demonstrated how experienced teachers revised weaker and stronger framing options in the fray of practice on a 'case by case basis' according to interactions with individual students (p.187). Similarly, the possibilities and practicality of 'weaving' modes of pedagogical framing across a middle primary science unit were explicated by Exley and Luke (2010) who posited that it is 'only through these shifting frames that teachers and learners can both engage with key facts, concepts and procedures with some degree of accuracy and precision; and connect with (students') background knowledge...' (p.36).

\section{Research context}

The data for this article was collected by Richard-Bossez, a PhD candidate seeking to examine the pedagogical processes of knowledge building in French preschools. In France, the école maternelle (nursery school) is part of the national school system, catering for $100 \%$ 
of the three to six year old children. There is a dearth of research literature on the forms and effects of pedagogic relations made available in literacy teaching and learning in the French context. Nevertheless, research by Duru-Bellat (2003) shows that the differences between the school performances of French students aged four to five years correlate with their social backgrounds, and in an indictment on the system, these differences increase during the schooling process. More recently, other classroom-based observations documented by Bautier (2008), Joigneaux (2009) and Lappara (2011) focused on students' social backgrounds vis-à-vis participant opportunities for increased learning outcomes via an investigation of the role of pedagogical differentiation in schooling contexts. Despite a shared focus on socially-just practices that develop individual capabilities in and through literacy teaching and learning, none have honed in on developing technical print-based competences.

The data were collected across 2010-2011, and are based on observations of literacy teaching and learning in six classes of grande section (third and last year of école maternelle for the 56 year olds) that contained children representing a range of social backgrounds. The data corpus is composed by the transcription of a hundred hours of observations, made up of 5 to 7 weeks in each class. The data are of different kinds: audio recordings, field notes, pictures of the classroom and the children's work and interviews with the teachers of the classes [1].

The lesson investigated in this paper takes place in a school hosting children from low-socioeconomic backgrounds and coming from different cultural and linguistic histories. This case study doesn't propose to be representative of what happens in every early years classroom, nor does it claim that the sample lesson is exemplary practice that should be replicated. Indeed there are several elements of this lesson that might seem to be less than good practice for literacy teaching and learning. This lesson was selected for further analysis because it shows different phenomenon which contribute to the differential construction of knowledge for the different students. As such we do not comment on the lesson in an evaluative sense, but neither do we suggest the lesson be used as a model for literacy teaching and learning, or indeed for working with those students who are considered at-risk of educational failure. We also recognise that this small snapshot of this teachers' practice may or may not be representative of her teaching style more generally.

To analyse the framing of the pedagogical relations and thus the forms of dis/enablement, we focused on the verbal transcripts of the teacher's and students' talk, noting the practices of 
pedagogical framing. In line with the theorization introduced, the pedagogical framing is described as stronger framing (represented with $+\mathrm{F}$ ), or weaker framing (represented with $-\mathrm{F}$ ) for a range of instructional and regulative discourses. For example, a stronger framing $(+\mathrm{F})$ of regulative discourse is evidenced when the teacher uses an injunction, 'Get your thumb out of your mouth'. A relatively weaker framing $(-\mathrm{F})$ of instruction discourse is evidenced when the teacher asks open questions such as 'What is to be done?'.

\section{The lesson: Matching lower and upper case letters}

In Marie's class during this observation, as is the case in many classes of école maternelle, approximately 30 young students are working in four groups of between 5 and 8 students. Each group rotates through four literacy-based workshops over the course of the week. As schooling in France is generally conducted over four days (typically Monday, Tuesday, Thursday and Friday), each group completes one workshop per school day. All four workshops are explained to the whole class on Monday during a collective moment with the class seated on a carpet around the feet of the teacher. Each workshop is once again briefly reviewed at the start of each day. Typically, the teacher stays at one workshop for the entire week whilst the other groups work independently.

The sequence analysed here takes place on a Thursday with five students: Chérif, Asma, Mohamed, Henri and Farid (pseudonyms). They are required to individually complete a worksheet connected to a story book read in class, 'Yumi'. 'Yumi' is a book about a little Japanese girl named 'Yumi'. The students' task is to transcribe six lower case words from the text - yumi, éventail, kimono, sakumi, bamoo and cerf-volant - into upper case in the blank spaces provided (see Figure 1). It is important to note that some of this vocabulary is French (e.g. cerf-volant) whilst other words are Japanese words and thus not everyday vocabulary for the students (e.g. kimono). A table indicating the correspondence between lower and upper case letters is at the bottom of the worksheet. For the purpose of this article, we explicitly denote lower case letters by using the adjective 'lower case' and situating the target letter in single quotation marks (e.g. lower case 'i'). Similarly, we explicitly denote upper case letters by using the adjective 'upper case' and situating the target letter in single quotation marks (e.g. upper case 'Z'). 


\section{[INSERT FIGURE 1 HERE]}

The lesson occurred over four movements: the collective explanation of the worksheet by the teacher on two occasions, the independent group work and interactions between the teacher and individual students in the concluding movement. We analyse the framing of the instructional and regulative discourses of each movement to provide answers to the overarching research question.

\section{Movement 1: The collective explanation on Monday}

The collective explanation of the worksheet took place on Monday when Marie introduced the class to all four workshops. For this particular workshop, she held up the worksheet and the students responded:

- 'She is there, Yumi ?'

- 'Have we got this story, Mademoiselle?'

- 'It's Yumi, the little girl, the little Japanese doll'

- 'Oh, I’ve seen Yumi!'

- 'Mademoiselle , I've seen Yumi and her little animal!'

The possibility of misinterpretation of the drawings shows through when one of the boys calls out 'poisson' (fish) for the sixth drawing, but it was of a kite in a fish form, so the target word is 'cerf-volant' (kite).

Marie explained the worksheet to the students:

"I put the words of the book of Yumi and I'll ask you to write them in upper case in pencil. [...] So, you look... So, here, there is 'yumi' written, I'll ask you, underneath, to write 'YUMI' in upper case. Here, I have written it in lower case (the teacher shows the words written on the work-sheet). [...] The alphabet, you've got it underneath in lower case and in upper case. So, if, for example, the (lower case) ' $y$ ', you don't know how to do it in upper case, you look for the (lower case) ' $y$ ' at the bottom, and underneath, it's in upper case. So, you look at the bottom if you don't know how to do the letter, OK?" 
However, the teacher's instructions do not stand-alone. The different notices and posters hanging on the walls of the classroom become part of the pedagogic discourse when a boy prompts the teacher asking, 'Upper case, how is it?'. To support her answer, the teacher points to a salt dough alphabet hung on the wall, 'The upper case, it's the letters which are up there, in salt dough, up there'. We also note the absence of discussion on text user practices (Luke \& Freebody, 1999), for example the social meaning of using words solely written in upper case.

In theoretical terms, Movement 1 moved through a range of weaker $(-F)$ and stronger $(+F)$ framings of instructional and regulative discourses. The weakest framing of instructional discourse was the teacher showing the worksheet and awaiting a response from the students. As their responses did not align to the aims of the lesson, Marie tightened the framing by taking control of the regulative discourse ('So, you look...') and the instructional discourse ('I'll ask you to write them in upper case in pencil'). Through these discourses, the teacher explicated both the conduct, character and manner required of the students (regulative discourse) as well as the content to be mastered (instructional discourse).

\section{Movement 2: The collective explanation on Thursday}

On Thursday, the day the target group worked on the transcription worksheet, Marie commenced with a collective briefing. She held up the worksheet and posed the rhetorical question, 'What is to be done?'. She copied the first word, 'yumi', on the board in lower case and demonstrated how to use the alphabet table at the bottom of the worksheet to complete the blank boxes in upper case. One student recalled, 'If I don't know, I look there [pointing the salt dough letters on the wall]'. It is important to note that one student from the target group, Henri was absent from this movement as he was working with a specialist support teacher. We draw attention to Henri's situation as he is considered at-risk of educational failure and his learning outcomes are of significant interest to us.

In theoretical terms, Movement 2 was strongly framed $(+F)$ with Marie in control of the instructional and regulative discourses. The framing was not so strong that there was no space for a student to make a comment within the acceptable limits of the regulative discourse. 


\section{Movement 3: Independent group work}

At the beginning of Movement 3, each group moved to their assigned working areas. Marie sat with another group at the same time as Henri entered the classroom and sat with Chérif, Asma, Mohamed and Farid to complete the translation worksheet. Four core events took place during Movement 3.

- Chérif completed his worksheet without reference to the alphabet table. He drew on his already existing knowledge base of alphabet translations. He occupied himself by chatting to his peers, saying the names of the letters and trying to sound them out. For example, he tried to read 'Bamboo' by pronouncing 'bbb'. He responded to a request from Mohamed to explain the task and then chatted about the word 'éventail' (fan), noting no sound corresponded to the letter ' $n$ ', explaining that it is a 'dumb (silent) letter' but still must be written.

- Asma completed her worksheet almost independently and using the alphabet table as instructed. She paused at the lower case ' $i$ ' and its upper case translation ('I'), the typography of the upper case letter 'I' with the horizontal serifs top and bottom confounding her. She turned to the researcher who was observing, asking, 'Is that it, the (upper case) 'I'?'. The researcher explained that the students had to work independently. Chérif passed by and pointed to the upper case 'I'. Asma asked, 'How did you do the (upper case) 'I'?'. Chérif responded, 'Just a line.' Asma wrote a vertical line on her worksheet.

- Farid did not work alone; Marie sought him out as she walked around the room. She noted that Farid commenced writing the individual letters from the right end of the word, moving to the left end. She told Farid, 'That is not the good way. Please begin to write from the left side.'

- When Henri returned to class, he sat with his thumb in his mouth. Marie left the group with which she was working, approached Henri and said, 'Get your thumb out of your mouth.' She directed Henri to the worksheet by pointing to lower case ' $y$ ' in 'yumi', and asked, 'What is the name of the first letter?' Henri answered, 'L.' She said, 'No, it's ' $y$ ', and showed Henri how to use the alphabet-table to transcribe lower and upper case letters. She repeated the demonstration with the second letter in 'yumi', lower case ' $u$ ', and then returned to her group. Henri continued, sometimes transcribing the letters and at other times copying the lower case letters into the boxes, all the time being very particular about adding serifs as seen on the worksheet. For example, when writing the upper case 'I', Henri reproduced the top and bottom horizontal lines. On a walk by, the teacher reminded Henri, 'You don't have to do the little lines; the (upper case) 'I' is just one line.' 
In theoretical terms, the independent group work realised a range of stronger $(+\mathrm{F})$ and weaker (-F) framings of instructional and regulative discourses. The worksheet provided a relatively stronger framing $(+\mathrm{F})$ of the regulative discourse in that it set out the selection, sequencing, pacing and a relatively stronger framing $(+\mathrm{F})$ of the instructional discourse by explicating the criteria to be acquired. For example, the empty box for each answer acted as stronger framing; none of the students forgot any letters in the words, as tends to happen when framing for answers is weaker. The alphabet table provided stronger framing for students such as Asma who needed support to complete the task. The teacher's absence, however, weakened the framing of the regulative discourse that created a space for Chérif, Mohamed, Farid and Henri to alter the pedagogic relations with different outcomes.

Chérif was able to take the opportunities provided by the weakened framing to alter the selection, sequencing and pacing of instruction as well as bringing in new knowledge. Even when the framing is weaker, this type of student can manage to display other internalised knowledges for the benefit of other students. For Asma, this lesson was a genuine training for handling the technical demands of lower to upper case transcription. She demonstrates some internalized competencies, but not all 26 translations are understood equally. The weaker pedagogical framing enabled her to source stronger framing of instructional discourse from Chérif. Mohamed slowed the pacing of instruction as he sought clarification from Chérif. Marie strengthened the framing for Farid by specifying that he needed to commence writing on the left hand side. The stronger context specific framing of the instructional and regulative discourses offered Farid an extra level of support. In contrast, the weaker framing permitted Henri to dilute the task to something else, which meant that he was not fulfilling the evaluative criteria set by the teacher. The important point is that the weaker framing of group work met the needs of Chérif, Asma and Mohamed, but failed Farid and Henri. Marie strengthened the pedagogical framing for Farid but not Henri. Thus in terms of the understandings of social justice underlying this analysis (see Schraad-Tischler, 2011), equal opportunity for self-realisation has not been guaranteed for each individual through the targeted investment in the development of individual capabilities. In short, this analysis exposes the teacher's pedagogical choices constraining Henri's learning and not providing him with equal access to the knowledges being valued. 


\section{Movement 4: The interactions between the teacher and the students}

In Movement 4, Marie returned to the group work table and engaged with each of the students one-on-one. This movement raised both ethical and pedagogical tensions for us as researchers. Whilst we are firmly committed to identifying and reporting on pedagogical practices that tend towards if not achieve socially just learning outcomes for all students, we deliberated over the need to report on Marie's separate interactions with the two students most at-risk of educational failure, that is Farid and Henri. Our deliberations centered on our professional discomfort with publically labeling one teacher's public responses to the students' inability to perform the required tasks as inappropriate. However, our responsibility as researchers is to provide full and accurate descriptions of what is taking place in contexts of teaching and learning and to provide conclusions that consider the total experiences for all students, including those at-risk of educational failure. Thus, we record the following five dot points for Movement 4.

- Marie validated the individual worksheets from Chérif and Asma.

- Marie erased Mohamed's incorrect answers and left him alone to continue working through the exercises again.

- Marie asked Farid, 'Find the (lower case) letter ' $t$ '.' He hesitated, so she asked him to describe its form. Farid responded, 'A cane and a line' and located it in the alphabet table. Instead of copying the upper case ' $\mathrm{T}$ ', he replicated the lower case form. She erased his effort and showed him the upper case ' $\mathrm{T}$ ' on the alphabet table and how to transcribe it into the blank space. She then erased her effort and asked him to find the upper case ' $T$ ' in the alphabet table. Farid didn't succeed, so she prompted him to look in the first line of the alphabet table again. Farid located the lower case ' $t$ ' and again copied the lower case ' $t$ ' in the box. Marie scolded, 'But, it's not difficult! You must write the letter underneath.' Farid succeeded at his third attempt at the transcription task for the upper-case ' $T$ '.

- For Henri, the one-on-one interactions with Marie occurred over two different moments. In the first moment, Marie came and sat beside him and without verbalizing, pointed to the lower case ' $n$ ' in the alphabet table. Henri wrote a lower case ' $u$ ' in the blank answer space. The teacher's frustration showed as she chided, 'You get on my nerves, you are really... tired !'. Marie showed Henri the upper case ' $\mathrm{N}$ ' in the alphabet table but Henri wrote a lower case ' $\mathrm{n}$ ' in the blank answer space. She responded, 'So, you, that's enough!' She took his paper, then handed it back to him and asked him to write his name on it. Henri complied and walked away.

- Marie called to Henri and explained, 'This letter, it's the (lower case) 'n', it's here (points to table), you must write the (upper case) letter that is underneath'. Henri completed the upper case ' $\mathrm{N}$ ' 
successfully. She pointed to the lower case ' $t$ ', said the name of the letter, located it in the alphabet table and then asked him which letter will he write. Henri pointed to the upper case 'T' but said, 'I don't know how to write it'. Marie offered, 'A line down and a line across the top.' Henri completed this transcription successfully. The next letter is lower case 'a'. Marie asked Henri the name of the letter, prompting, 'This one, you know it, it's in your name' [2]. Henri answered correctly and wrote the upper-case ' $A$ '. When transcribing the lower case ' $\mathrm{i}$ ' to upper case 'I', he added the top and bottom serifs as shown in the alphabet table, but Marie sighed, 'You don't need to do the lines, the (upper case) 'I' is just one line.' She sub-vocalised the letter name and again explained how to scribe the letter. For the upper case 'N', she demonstrated on the paper and Henri's first attempt was not right. He grimaced and looked at his teacher as she erased the letter. He tried again, this time with success. This triadic sequence was replicated as Henri transcribed lower case ' $a$ ' and ' $k$ ' to upper case ' $A$ ' and ' $K$ '. At the end of the time allocated to the lesson, Henri had not finished the worksheet. Marie asked him to place his paper on the rack, noting, 'We will finish later.'

In theoretical terms, the range of framing options woven throughout the instructional and regulative discourses in Movement 4 once again realised different outcomes for each of the students. For Chérif and Asma, Movement 4 affirmed their status as successful beginning readers and writers. For Mohamed and Farid, the stronger framing $(+F)$ of instructional discourse provided the structure for them to finish the task successfully. In Mohamed's case, the stronger framing $(+\mathrm{F})$ of instructional discourse identified the incorrect responses requiring his attention. In Farid's case, the stronger framing $(+F)$ of instructional discourse provided another explanation of the task at hand. At the same time, the weakened framing (F) of regulative discourse made available via the structure of group work permitted Farid's needs to be met through 3 repetitions of the instructions. This is an example of pedagogical weaving that works toward socially just ends.

For Henri, the weakest framing (-F) of instructional discourse was instituted when Marie pointed to the lower-case ' $n$ ' without verbalizing. The expectation was that Henri would locate the upper-case ' $\mathrm{N}$ ' and transcribe this into the blank space. This movement towards invisible pedagogy disguised the evaluative criteria for Henri; he was not able to perform until the evaluative criteria was explicit. In the moments when Marie offered a stronger framing $(+F)$ of the regulative discourse with no strengthening of the framing of the instructional discourse, Henri was not able to progress his knowledge base. It was Marie's 
pedagogical response to Henri that also marginalised him from his peers and marginalised him from the instructional discourse. It will be recalled, from the viewpoint of social justice, Young (1990) claims marginalisation is perhaps the most dangerous form of oppression. This is thus the most extreme example of socially unjust pedagogy in this account.

We are not sure what motivated Marie to instigate a second moment of one-on-one interaction with Henri. We're not sure if it was because a researcher was in the room, or if it was part and parcel of Marie's pedagogical practice to persevere with the literacy teaching and learning task for students at-risk of educational failure. In this second moment, the selection, sequencing, pacing and evaluative criteria were strongest when Henri worked with Marie to transcribe the upper case ' $\mathrm{N}$ ' towards the end of the movement. This stronger framing $(+\mathrm{F})$ realised a degree of success in that some aspects of the instructional discourse were completed. However, this moment once again affirmed Henri's identity and status as a struggling reading and writer, not only to himself, but also to those who witnessed Marie's ongoing public commentary in the first and second moments of movement 4 . Thus the final moment of this movement is still constituted as an example of socially unjust pedagogical weaving because Marie has not, in the words of Schraad-Tischler (2011), guaranteed each individual 'genuinely equal opportunities for self-realisation through the targeted investment in the development of individual 'capabilities' (p. 11, emphasis in original).

\section{Conclusion}

Unlike the mapping of framing practices at the level of the lesson (e.g. Exley \& Luke, 2010), this more delicate analysis of a single lesson has allowed us to see which early years students were dis/enabled as what types of literacy learners through which pedagogical practices. This analysis thus showcased the utility of Bernstein's notions of stronger and weaker framing of instructional and regulative discourses for providing the conceptual tools for lesson analysis.

The findings were that a stronger framing of the instructional discourse was realized through a more visible pedagogy and although this invested the teacher with control of the pedagogical relationship, it served to redistribute the literacy resources of lower and upper case transcriptions to the student deemed most at-risk of educational failure, that is the student who had the least interiorized alphabet transcription resources. In contrast, when the 
framing was weakened, this student did not benefit from the additional control often accorded to students when the pedagogy is more invisible.

There was also an occurrence where the teacher's stronger framing of the regulative discourse blocked access to the instructional discourse for this student. This was the incident when the teacher expelled the student from the teacher's support. The student's insufficient interiorized knowledge of the instructional discourse meant he could not take responsibility for completing the assigned task. For this student, the take up of particular pedagogical practices was critical if the ultimate goal is to interrupt the systemic inequities associated with students deemed at-risk of educational failure. The high level of teacher control of the regulative discourses also, regrettably, permitted this at-risk student no access to the discourses that were overtly constructing him as frustrating, a failure and undeserving of the teacher's ongoing instruction.

For other students, for example, Chérif, who had a substantial internalized knowledge base for the task at hand, and Asma, who required instructions to be repeated and specific questions to be answered, the weaker framing of the instructional discourse through the invisible pedagogy of group work was advantageous. For Chérif, greater control of the pedagogical relationship meant he could expand the selection, sequence and evaluative criteria and speed up the pacing of instructional discourse without compromising his display of the teacher sanctioned targeted learning outcomes. For Asma, greater control of the pedagogical relationship afforded her the opportunity to slow down the pacing of instructional discourse by having Chérif revoice the processes for completing the task. The more invisible pedagogy also permitted her the opportunity to alter the intended sequence of engagement, that is to work independently and take the work to a teacher for evaluation.

Our concluding case here is simple: different framings have potentially different cognitive and social effects that constitute different kinds of literacy knowledge and subject positions for different students. In short, the constant weaving of visible and invisible pedagogy did not produce the same effects for all students. Accessing the set of cognitive skills for literacy learning was dependent upon each student's level of interiorized transcription knowledge for completing the task at hand. Similar to the findings of Pandraud's (2011) doctoral dissertation on language learning in French primary schools, choices of pedagogical framing are not only complicated for the teacher, but have very real effects on students' learning and their current 
and future opportunities. Our final point of discussion returns to the overarching theme of this special edition, that of social justice in early years education. In this case study we see choices in pedagogical framing providing socially just and socially unjust teaching and learning practices. Whilst the notion of literacy as a social practice (see, for example, Janks, 2010) rightly receives much attention, we submit that what happens in the name of pedagogical framing in lessons focused on teaching the cognitive skills of literacy learning to at-risk learners also warrants careful attention. As demonstrated by Young's (2010) work on inclusion and democracy issues of justice vary for structurally different groups.

\section{Endnotes}

1. All data were generated, collected and transcribed in French, but this target lesson was translated to English by Richard-Bossez, a native Francophone and accomplished English as Foreign Language user, for the purpose of publishing in an English medium journal with Exley.

2. In order to conserve the anonymity of the students, the students' names have been changed.

\section{Reference List}

Ball, E.W. \& Blachman, B. A. (1991) Does phonemes awareness training in kindergarten make a difference in early world recognition and developmental spelling?, Reading Research Quarterly, 26, 49-65.

Bautier, E. (dir.) (2008) Apprendre à l'école, apprendre l'école: Des risques de construction d'inégalités dès la maternelle. Lyon : Chronique Sociale.

Bernstein, B. (1977) Class, codes and control: Vol. 3. London: Routledge \& Kegan Paul.

Bernstein, B. (1996) Pedagogy, symbolic control and identity: Theory, research, critique. Oxford: Rowman \& Littlefield Publishers.

Bissex, G. (1980) Guys at work: A child learns to write and read. Cambridge, MA: Harvard University Press.

Bowey, J. A. (2005) Predicting individual differences in learning to read. In M. J. Snowling \& C. Hulme (Eds.) The Science of Reading: A Handbook. Malden, MA: Blackwell Publishing Ltd. 
Cardoso-Martins, C., Resende, S. M., \& Rodrigues, L. A. (2002) Letter name knowledge and the ability to learn to read by processing letter-phoneme relations in words: Evidence from Brazilian Portuguese-speaking children, Reading and Writing, 15, 409-432.

Cazden, C. (2006, January) Connected learning: Weaving in classroom lessons. Keynote address, Pedagogy in Practice 2006 Conference, University of Newcastle, Australia, January 18, 2006.

Cloran, C. (2008) Contexts for learning. In F. Christie (Ed.) Pedagogy and the Shaping of Consciousness. London: Continuum.

Duru-Bellat, M. (2003) Les inégalités sociales à l'école: Genèse et mythes. Paris: Presses Universitaires de France.

Ecalle, J., Biot-Chevrier, C., \& Magnan, A. (2008) Alphabet knowledge and early literacy skills in French beginning readers, European Journal of Developmental Psychology, 5(3), 303-325.

Exley, B. (2008) Communities of Learners: Early Years Students, New Learning Pedagogy, \& Transformations. In A. Healy (Ed.) Multiliteracies \& Diversity in Education: New Pedagogies for Expanding Landscapes. Oxford University Press: South Melbourne.

Exley, B. \& Luke, A. (2010) Uncritical framing: Lesson \& knowledge structure in school science. In D. Cole (Ed.) Handbook of Research on Multiliteracies \& Technology Enhanced Education. Routledge: London.

Freire, P. \& Macedo, D. P. (1987) Literacy: Reading the Word and the World. London: Routledge.

Hallet, E. (2008) Signs and Symbols: Children's engagement with environmental print. In J. Marsh \& E. Hallet (Eds.) Desirable Literacies: Approaches to Language and Literacy in the Early Years. London: UKLA.

Halliday, M.A.K. (1978) Language as Social Semiotic: The social interpretation of language and meaning. London: Edward Arnold.

Heath, S. B. (1983) Ways with Words. Cambridge: Cambridge University Press.

Janks, H. (2010) Literacy and Power. London : Routledge. 
Joigneaux, C. (2009) «La construction de l'inégalité scolaire dès l'école maternelle». Revue française de Pédagogie, 169, octobre-novembre-décembre 2009.

Kwek, D. (2012) Weaving as frontload and backend pedagogies: Building repertoires of connected learning. In C. Day. (Ed.) The Routledge Interntional Handbook of Teachers and School Development. New York, NY: Routledge.

Levin, I., Patel, S., Margalit, T., \& Barad, N. (2002) Letter names: Effect on letter saying, spelling, and word recognition in Hebrew, Applied Psycholinguistics, 23, 269 - 300.

Luke, A. \& Freebody, P. (1999) A map of possible practices, further notes on the four resource model, Practically Primary, 4(2), 5-8.

McBride-Chang, C. (1999) The ABCs of the ABCs: The development of letter-name and lettersound knowledge, Merrill-Palmer Quarterly, 45, 285 - 308.

Naslund, J. C., \& Schneider, W. (1996) Kindergarten letter knowledge, phonological skills, and memory processes: Relative effects on early literacy, Journal of Experimental Child Psychology, 62, $30-59$.

Pandraud, N. (2011) The recontextualisation of scientific knowledge and learning activities: translating the French-language curriculum into the writing of a tale in a class de 6e. In D. Frandji \& P. Vitale (Eds.) Knowledge, Pedagogy and Society: International perspectives on Basil Bernstein's sociology of education. London: Routledge.

Paris, S. (2005) Reinterpreting the development of reading skills, Reading Research Quarterly, 40, 2, 184-202.

Ramognini, N. (2011) Reading Basil Bernstein: A socio-epistemological point of view. In D. Frandji \& P. Vitale (Eds.) Knowledge, Pedagogy and Society: International perspectives on Basil Bernstein's sociology of education. London: Routledge.

Salonen, P., Lepola, J., \& Niemi, P. (1998) The development of first graders' reading skill as a function of pre-school motivational orientation and phonemic awareness, European Journal of Psychology of Education, 13, 155 - 174. 
Seymour, P. H. K., Aro, M., \& Erskine, J. M. (2003) Foundation literacy acquisition in European orthographies, British Journal of Psychology, 94, 143 - 174.

Sprenger-Charolles, L., \& Bonnet, P. (1996) New doubts on the importance of the logographic stage, Cahiers de Psychologie Cognitive/Current Psychology of Cognition, 15, 173 - 208.

Stavrou, S. (2011) Reviewing recontextualisation of knowledge at university: From Bernstein's theory to empirical research. In D. Frandji \& P. Vitale (Eds.) Knowledge, Pedagogy and Society: International perspectives on Basil Bernstein's sociology of education. London: Routledge.

Schraad-Tischler, D. (2011) Social Justice in the OECD - How Do the Member States Compare? Sustainable Governance Indicators 2011. Gutersloh, Germany: Bertelsmann Stiftung.

Woods, A. F. \& Henderson, R. (2008) The early intervention solution: Enabling or constraining literacy learning, Journal of Early Childhood Literacy, 8(3), 268-276.

Worden, P. E. \& Boettcher, W. (1990) Young children's acquisition of alphabet knowledge. Journal of Reading Behavior, 22(3), 277-296.

Young, I. M. (1990) Justice and the Politics of Difference. Princeton, New Jersey: Princeton University Press.

Young, I. M. (2010) Inclusion and Democracy. New York: Oxford University Press. 
Figure 1: Asma's work-sheet

DECOUVRIR L'ECRIT Faire la correspondance entre I'écriture script et celle en capitales d'imprimerie Ecris le nom de chaque élément relevé dans Palbum YUMI en lettres majuscules.

\begin{tabular}{|l|l|l|l|}
\hline$y$ & $u$ & $m$ & $i$ \\
\hline & $U$ & $M$ & 1 \\
\hline
\end{tabular}

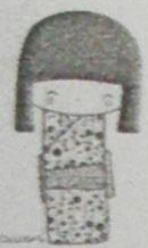

\begin{tabular}{|l|l|l|l|l|l|l|l|}
\hline é & v & e & n & t & a & i & 1 \\
\hline F & V & E & N & j & A & l & U \\
\hline
\end{tabular}

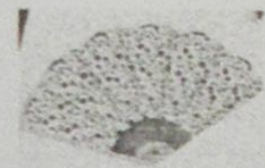

\begin{tabular}{|c|c|c|c|c|c|}
\hline $\mathrm{k}$ & i & $\mathrm{m}$ & 0 & $\mathrm{n}$ & 0 \\
\hline$K$ & & $M$ & 0 & & 0 \\
\hline
\end{tabular}

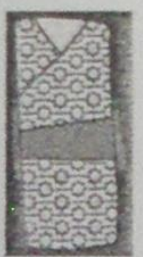

\begin{tabular}{|l|l|l|l|l|l|}
\hline $\mathrm{s}$ & $\mathrm{a}$ & $\mathrm{k}$ & $\mathrm{u}$ & $\mathrm{m}$ & $\mathrm{i}$ \\
\hline $\mathrm{S}$ & $\mathrm{A}$ & $\mathrm{K}$ & $\mathrm{U}$ & $\mathrm{v}$ & $\mathrm{I}$ \\
\hline
\end{tabular}
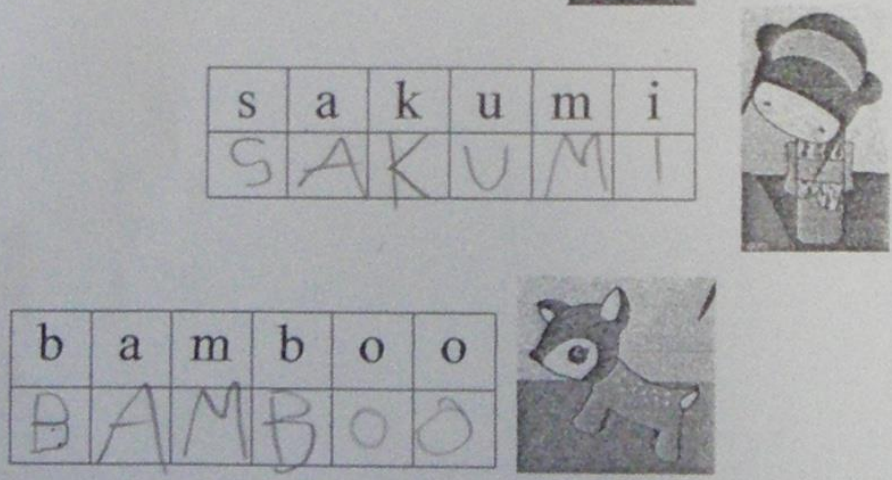

\begin{tabular}{|c|c|c|c|c|c|c|c|c|c|c|}
\hline c & e & $r$ & $\mathrm{f}$ & - & V & 0 & 1 & $\mathrm{a}$ & $\mathrm{n}$ & $\mathrm{t}$ \\
\hline & $E$ & $R$ & $F$ & - & & & & & & \\
\hline
\end{tabular}

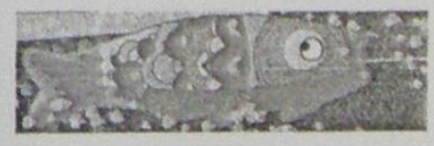

\begin{tabular}{|l|l|l|l|l|l|l|l|l|l|l|l|l|l|l|l|l|l|l|l|l|l|l|l|l|l|}
\hline a & b & c & d & e & f & g & h & i & j & k & l & m & n & o & p & q & r & s & t & u & v & w & x & y & z \\
\hline A & B & C & D & E & F & G & H & I & J & K & L & M & N & O & P & Q & R & S & T & U & V & W & X & Y & Z \\
\hline
\end{tabular} 